(2) Open Access Full Text Article

\title{
Intraoperative complications of refractive small incision lenticule extraction in the early learning
}

\section{curve}

This article was published in the following Dove Press journal:

Clinical Ophthalmology

\author{
Abdelmonem M Hamed ${ }^{1,2}$ \\ Shereef M Abdelwahab ${ }^{1,2}$ \\ Tarek T Soliman ${ }^{1,2}$ \\ 'Ebsar Eye Center, Benha, Qalyubia, \\ Egypt; ${ }^{2}$ Ophthalmology Department, \\ Benha University, Benha, Qalyubia, \\ Egypt
}

\begin{abstract}
Purpose: To study the intraoperative complications of refractive small incision lenticule extraction (ReSMILE push-up technique), and to record the mean intraoperative duration time of all surgeries for the refractive surgeon in his early learning curve.

Setting: Ebsar Eye Center, Benha, Egypt.

Design: A prospective, single-center, cohort clinical study.

Methods: This prospective, single-center, cohort clinical study was done on patients with myopia and myopic astigmatism, who were enrolled for SMILE surgeries. All the SMILE operations were performed by a single refractive surgeon (AMH), by using only the ReSMILE push-up technique.

Results: A total of 190 eyes were operated upon, using the (ReSMILE push-up technique), with a mean follow-up period of 2 months. The intraoperative complications have been recorded for all patients. The mean operative duration of all cases was $4.45 \pm 1.45$ minutes.

Conclusion: The ReSMILE: push-up technique seems to facilitate visualization of the edge of the lenticule of the SMILE surgery, especially for the refractive surgeon in his early learning curve.
\end{abstract}

Keywords: ReLEX, SMILE, ReSMILE, refractive, SMILE complications

\section{Background}

Although the femtosecond laser has been used for over a decade to cut laser-assisted in situ keratomileusis (LASIK) corneal flaps with high precision, the evolution of small incision lenticule extraction (SMILE) has resulted in a paradigm shift in refractive surgery. ${ }^{1-3}$

SMILE comprises the creation of a lenticule of corneal stroma using femtosecond laser, which is then extracted through a $2 \mathrm{~mm}$ incision. SMILE avoids all the flap complications associated with LASIK, including incomplete, irregular or thin flaps, button holes and free caps. In addition, it has been shown to preserve the strong anterior corneal lamellae, resulting in better long-term biomechanical stability as well as less postoperative dry eye due to the preservation of corneal nerve endings and thus faster and more comfortable visual recovery. ${ }^{4,5}$ SMILE is, therefore, a safe, predictable and efficacious method of refractive correction. ${ }^{4,6-8}$

The aim of this paper was to study the intraoperative complications of refractive small incision lenticule extraction (ReSMILE push-up technique) and to record the mean intraoperative duration time of all surgeries. ${ }^{9}$ The ReSMILE push-up technique facilitates a crucial step of the surgery, which is dissection of the lenticule. We aimed 
at measuring the mean duration time of the ReSMILE push-up technique for the refractive surgeon in his early learning curve of SMILE.

\section{Materials and methods}

This prospective, single-center, cohort clinical study was done on patients with myopia and myopic astigmatism, who were enrolled for SMILE between January 1, 2017, and March 27, 2017, in Ebsar Eye Center, Benha, Qalyubia, Egypt. Our study was approved by the Research Ethics Committee of Benha Faculty of Medicine, Benha University.

Inclusion criteria were as follows: patients $\geq 18$ years of age with no refractive change for at least 12 months, stable tear film and contact lens discontinuation for at least 2 weeks prior to surgery. Exclusion criteria included pachymetry readings $<500 \mu \mathrm{m}$, corneal ectasias, eg, keratoconus, corneal opacities, ocular surface disease and severe dry eye syndrome.

All patients underwent uncorrected and best-corrected distance visual acuity, manifest and cycloplegic refraction, applanation tonometry, slit lamp examination, dilated fundus examination and Scheimpflug corneal tomography (OCULUS Pentacam $^{\circledR}$; OCULUS Inc., Wetzlar, Germany).

All the SMILE operations were performed by a single refractive surgeon (AMH), by using only the ReSMILE push-up technique. The nature of the procedure was explained to the patients, and written informed consent was obtained in accordance with the tenets of the Declaration of Helsinki.

After administration of topical anesthesia (benoxinate hydrochloride $0.4 \%$ eye drops), the eye was sterilized, draped and a speculum was inserted. Centration was achieved by asking the patient to fix on a flashing green target. Docking with the curved interface cone and suction fixation was applied. The femtosecond laser creates the deep surface of the lenticule in a spiral in fashion, the lenticule border, the superficial surface in a spiral out fashion and the small incision in that order. Suction was released, and the eye is undocked.

All SMILE operations were done using the VisuMax FS laser system (Carl Zeiss Meditec, Jena, Germany). We used the following femtosecond laser parameters: from 100 to $140 \mu \mathrm{m}$ cap thickness, $7.5 \mathrm{~mm}$ anterior-plane cut diameter, $6.5 \mathrm{~mm}$ optical zone of lenticule and $160 \mathrm{~nJ}$ of energy with lenticule side-cut angles at $135^{\circ}$. A $3.0 \mathrm{~mm}$ entrance wound was created centered at 10:30 O'clock in all cases. The spot distance and tracking spacing were $4.5 / 4.5 \mu \mathrm{m}$ for the posterior lenticule plane, $2.5 / 2.5 \mu \mathrm{m}$ for the lenticule side-cut, $4.5 / 4.5 \mu \mathrm{m}$ for the anterior lenticule plane and $2.5 / 2.5 \mu \mathrm{m}$ for the entrance wound side-cut.

During the ReSMILE push-up technique, an instrument with a Y-shaped tip, the Bahr-Maltzman hook $(0.8 \mathrm{~mm}$

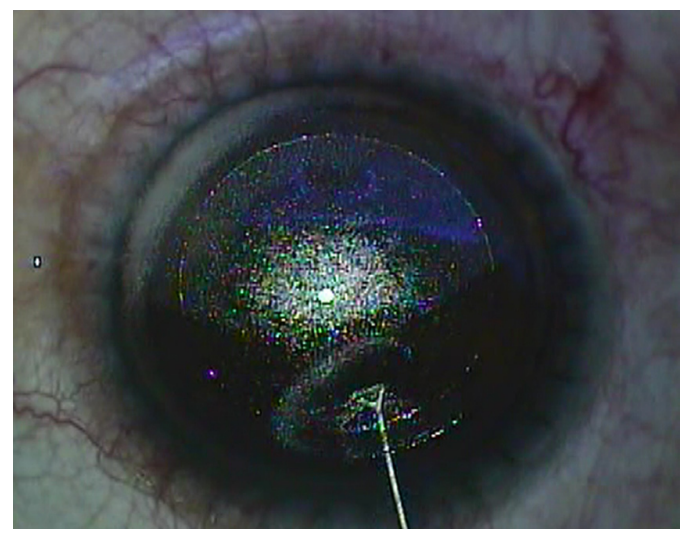

Figure I Edge of lenticule caught by $Y$-shaped instrument.

delicate tip, $10 \mathrm{~mm}$ angle to tip and $118 \mathrm{~mm}$ overall length; ASICO, Westmont, IL, USA, product code: AE-2219), was inserted through the small incision catching the edge of the lenticule between the 2 ends of its tip. The caught edge of the lenticule is then pushed up from its bed, making it much easier to recognize inside the pocket (Figure 1). ${ }^{9}$ A spatula, the SMILE Double Ended Dissector with Spoon Tip (Duckworth and Kent, Hertfordshire, UK, Product Number: 6-836), is then passed below the pushed-up lenticule edge, dissecting a linear area resembling a tunnel below the middle of the deep surface of the lenticule, then passed above the pushed-up lenticule edge to dissect the lenticule from the cap and finally passed below the lenticule to dissect the remainder of the deep surface of the lenticule and fold it to one side. A non-toothed serrated micro-forceps, the smile lenticular removal forceps (Duckworth and Kent, Product Number: 2-836), is finally used to extract the lenticule.

\section{Results}

One hundred ninety eyes were operated on, using the ReSMILE push-up technique, with a mean follow-up period of 2 months. Thirty-five eyes presented with surgical complications (18.42\%) (Table 1). They included: 1) Lost vacuum

Table I Distribution of intraoperative SMILE complications

\begin{tabular}{lll}
\hline Complications, $\mathbf{N}=\mathbf{I 9 0}$ & $\mathbf{n}$ & $\%$ \\
\hline Lost vacuum & 6 & 3.15 \\
Treatment decentration & 2 & 1.05 \\
Wound bleeding & 7 & 3.68 \\
Bubbles in the interface & 3 & 1.57 \\
Incomplete bubble separation & $\mathrm{I}$ & 0.52 \\
Epithelial defects & 5 & 2.63 \\
Incision tear & $2 \mathrm{I}$ & $1 \mathrm{I} .05$ \\
Cap rupture & $\mathrm{I}$ & 0.52 \\
Lenticule adherence to the cap & 0 & 0 \\
\hline
\end{tabular}

Abbreviation: SMILE, small incision lenticule extraction. 

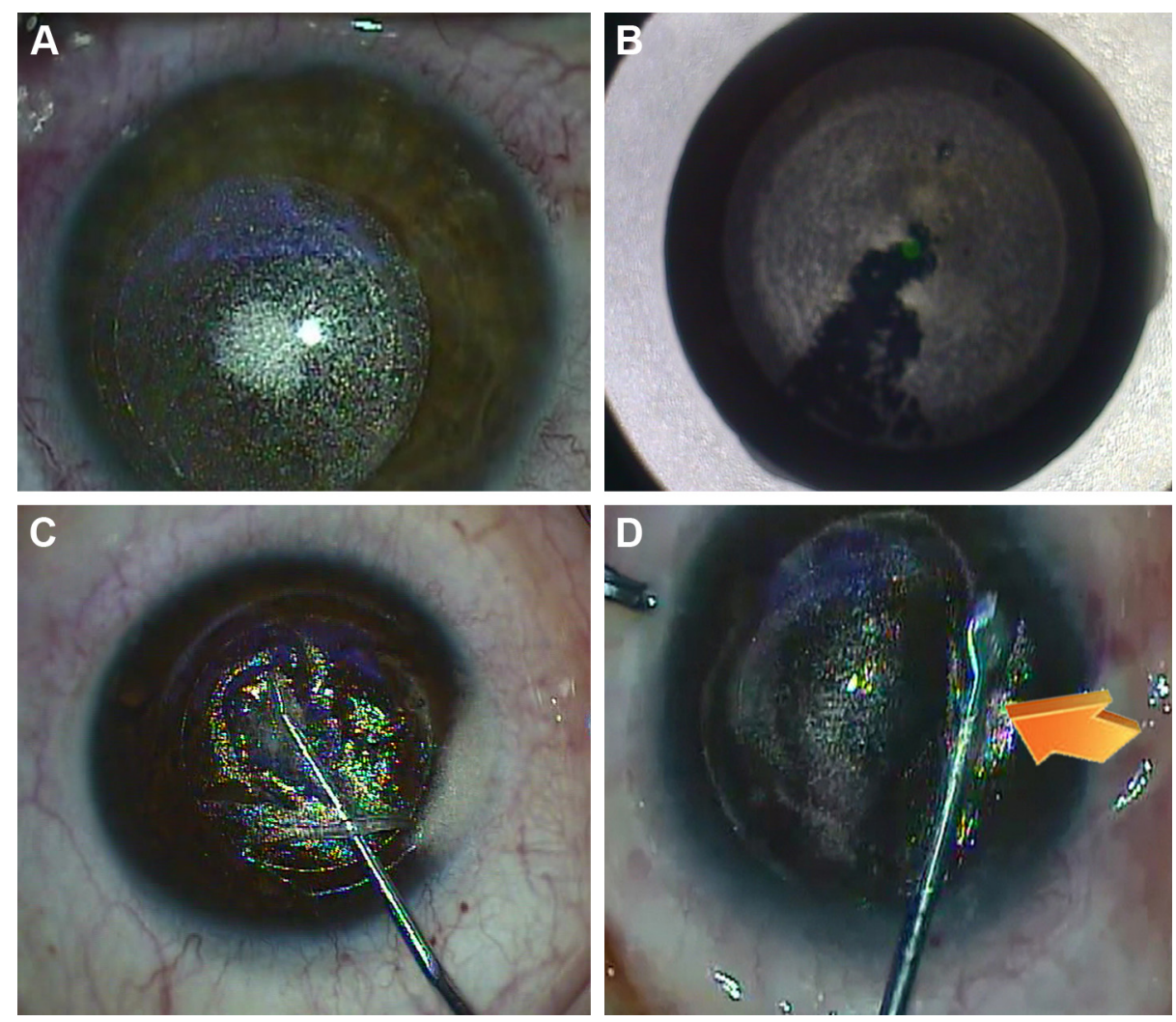

Figure 2 ReSMILE intraoperative complications.

Notes: (A) Lenticule decentration. (B) Black island during the creation of the lenticule. rupture during dissection.

Abbreviation: SMILE, small incision lenticule extraction.

that occurred in 6 eyes $(3.15 \%)$; in 4 eyes, the procedure was converted to Femtolasik, and in the other 2 eyes the treatment was continued as a SMILE using the same curved interface cone pack; 2) Treatment decentration in 2 eyes $(1.05 \%)$ (Figure 2A), in whom the operations were aborted; 3) Wound bleeding occurred in 7 eyes $(3.68 \%)$; 4) Bubbles in the interface occurred in 3 eyes $(1.57 \%) ; 5)$ Incomplete bubble separation occurred in 1 eye $(0.52 \%)$ (Figure $2 \mathrm{~B}$ ), which occurred due to Meibomian secretions adherence to the cone surface, in this case, the operation was aborted; 6) Epithelial defects occurred in 5 eyes (2.63\%); 7) Incision tear occurred in 21 eyes (11.05\%) (Figure 2C); and 8) Only 1 eye had cap rupture $(0.52 \%)$ (Figure 2D). Lenticule adherence to the cap did not occur in any of our cases. The mean operative duration of all cases was $4.45 \pm 1.45$ minutes.

\section{Discussion}

Laser refractive surgery has been performed for many years, and there have been tremendous advancements in terms of technique and technology, making it increasingly precise and highly predictable. ${ }^{10}$ Since the advent of SMILE, it has gained a reputation for being superior to LASIK regarding comfort and safety profile among surgeons and patients alike. This is largely due to avoidance of creation of a flap, thus avoidance of all flap-related complications of LASIK led SMILE to occupy an increasing share of our schedules as refractive surgeons. ${ }^{11}$

As we became more familiar with the technique of SMILE, we came to notice that the most challenging step of the surgery was identification of the edge of the lenticule during dissection. We also noticed that most of the intraoperative complications of the surgery resulted from the surgeon's inability to recognize the edge of the lenticule during his early learning curve. This forces the surgeon to keep trying to dissect under or above the lenticule for a long duration. These trials may lead to complications such as wound tear and cap or lenticule rupture, as well as longer operative duration time. Proper recognition of the edge of the lenticule should render the operation easy due to fast recognition of the lenticule with its under and upper surfaces, thus shortening the mean operative duration and minimizing intraoperative complications. $^{12}$

The ReSMILE push-up is a newly proposed technique (Video S1) carried out using an instrument with a Y-shaped tip to "push-up" the edge of the lenticule from its bed prior to dissection, and hence, it becomes more easily recognizable. ${ }^{9}$ 
The Y-shaped tip of the instrument is advantageous because it catches the edge of the lenticule easily between its 2 limbs (Figure 1). The surgeon is now better guided to both planes of dissection superficial and deep to the lenticule by passing the dissecting spatula above or below the "pushed-up" edge of the lenticule that can be easily seen (after pushing-up) under the coaxial light of the microscope. This gives the surgeon more confidence regarding where his spatula is heading and prevents him tumbling inside the pocket trying to find the planes of dissection (possibly causing wound tears), dissecting the deep surface first (causing lenticule adherence to the cap) or dissecting into an entirely new plane (and having to abort the operation) and hence reducing the risk of intraoperative complications and mean operative duration time as well.

In this study, the "ReSMILE push-up technique" has resulted in a mean operative duration time of 4 minutes during the early learning curve for the refractive surgeon who is unfamiliar with both SMILE and ReSMILE techniques, implying a potential positive impact, in terms of patient comfort, improving the overall health care process and reducing the incidence of postoperative corneal haze as well.

\section{Conclusion}

Although SMILE is a promising refractive surgery for the correction of myopia and myopic astigmatism with predictable refractive and visual outcomes, complications can occur. Most of these complications are related to the learning curve of refractive surgeon that can be minimized by choosing the familiar technique among the different SMILE techniques. Based on our study we concluded that the ReSMILE push-up technique is safer for the refractive surgeons in their early learning curve. However, more research studies are required to evaluate this new ReSMILE push-up technique and to compare it to the SMILE conventional technique published in the literature.

\section{Acknowledgment}

The authors did not receive any financial support from any public or private sources and have no financial or proprietary interest in a product, method, or material described herein.

\section{Disclosure}

The authors report no conflicts of interest in this work.

\section{References}

1. Slade SG. The use of the femtosecond laser in the customization of corneal flaps in laser in situ keratomileusis. Curr Opin Ophthalmol. 2007; 18(4):314-317.

2. Kim P, Sutton GL, Rootman DS. Applications of the femtosecond laser in corneal refractive surgery. Curr Opin Ophthalmol. 2001;22(4): 238-244.

3. Reinstein DZ, Archer TJ, Gobbe M. Small incision lenticule extraction (SMILE) history, fundamentals of a new refractive surgery technique and clinical outcomes. Eye Vis (Lond). 2014;1:3.

4. Shah R, Shah S, Sengupta S. Results of small incision lenticule extraction: all-in-one femtosecond laser refractive surgery. J Cataract Refract Surg. 2011;37(1):127-137.

5. Wang $\mathrm{Y}, \mathrm{Wu} \mathrm{Z}$, Tang $\mathrm{X}$, et al. Two millimeter micro incision lenticule extraction surgery with minimal invasion: a preliminary clinical report. Zhonghua Yan Ke Za Zhi. 2014;50(9):671-680.

6. Vestergaard A, Ivarsen AR, Asp S, Hjortdal JØ. Small-incision lenticule extraction for moderate to high myopia: predictability, safety, and patient satisfaction. J Cataract Refract Surg. 2012;38(11):2003-2010.

7. Sekundo W, Kunert KS, Blum M. Small incision corneal refractive surgery using the small incision lenticule extraction (SMILE) procedure for the correction of myopia and myopic astigmatism: results of a 6 month prospective study. Br J Ophthalmol. 2011;95(3):335-339.

8. Moshirfar M, McCaughey MV, Reinstein DZ, Shah R, SantiagoCaban L, Fenzl CR. Small-incision lenticule extraction. J Cataract Refract Surg. 2015;41(3):652-665.

9. Hamed A, Fekry A. Refractive small-incision lenticule extraction: push-up and push-down techniques. J Cataract Refract Surg. 2016; 42(12):1713-1715.

10. Alio J. Refractive surgery today: is there innovation or stagnation? Eye Vision. 2014;1:4.

11. Ang M, Tan D, Mehta JS. Small incision lenticule extraction (SMILE) versus laser in-situ keratomileusis (LASIK): study protocol for a randomized, non-inferiority trial. Trials. 2012;13:75.

12. Ramirez-Miranda A, Ramirez-Luquin T, Navas A, Graue-Hernandez EO. Refractive lenticule extraction complications. Cornea. 2015; 34(suppl 10):S65-S67.
Clinical Ophthalmology

\section{Publish your work in this journal}

Clinical Ophthalmology is an international, peer-reviewed journal covering all subspecialties within ophthalmology. Key topics include: Optometry; Visual science; Pharmacology and drug therapy in eye diseases; Basic Sciences; Primary and Secondary eye care; Patient Safety and Quality of Care Improvements. This journal is indexed on Submit your manuscript here: http://www.dovepress.com/clinical-ophthalmology-journal

\section{Dovepress}

PubMed Central and CAS, and is the official journal of The Society of Clinical Ophthalmology (SCO). The manuscript management system is completely online and includes a very quick and fair peer-review system, which is all easy to use. Visit http://www.dovepress.com/ testimonials.php to read real quotes from published authors. 